\title{
Theoretical analysis of vapour refrigeration cycle with hybrid refrigerant of different
} types and mixing ratios

\author{
Mushtaq Ismael Hasan, Jasim Mohsin Chitheer \\ Mechanical Engineering Department, College of Engineering, University of Thi-Qar, Iraq
}

\begin{abstract}
:
In this paper analytical study has been made to investigate a hybrid refrigerant consists of different refrigerants with different mixing ratios and find out its effects on the performance of cycle and specify the best refrigerant that gives best performance and least environmental pollution. Firstly the performance of vapor compression refrigeration system has been analyzed with several different pure refrigerants( R11, R12, R13,R22,R23, R32, R41, R115, R116, R124, R125, R134a, R142a, R143a, R152a) by REFPROP software and the values of coefficient of performance (COP) and mass flow rate $(\dot{m})$ and work in compressor $\left(\mathrm{W}_{\mathrm{c}}\right)$ for each pure refrigerant is calculated and by use other properties for every refrigerant it can determine the best refrigerants to make a new refrigerant that comes from mixing of two or three of pure refrigerants with best performance for example R22 and R134a with mixing ratios (25:75),(50:50),(75:25) respectively Assuming the evaporator temperature is $\left(-10{ }^{\circ} \mathrm{C}\right)$ and the condenser temperature is $\left(35^{\circ} \mathrm{C}\right)$. The main parameters are calculated such as new refrigerant, mass flow rate and work used in compressor for various capacity in $(\mathrm{kW})$. The results showed that the maximum performance recorded with R134a and the minimum value with R115 while the values of performance for their mixtures fluctuated between the maximum and minimum values for the pure refrigerants and the cause of this is due to combination of properties as boiling point temperature and critical temperature, latent heat of vaporization, specific heat of liquid and specific volume of the vapor.

Key words: Refrigerator, GWP global worming potential, ODP ozone depletion potential, TR, refrigerant, hybrid refrigerant, $\mathrm{pR}$ pure Refrigeration.
\end{abstract}

\section{NOMENCLATURE:}

$\mathrm{h} \quad$ Specific enthalpies of refrigerant $(\mathrm{kJ} / \mathrm{kg})$

COP Coefficient of performance

$\mathrm{P} \quad$ Pressure (bar)

T Temperature $\left({ }^{\circ} \mathrm{C}\right)$

$\dot{m} \quad$ Mass flow rate $(\mathrm{kg} / \mathrm{s})$

$\mathrm{Q}_{\mathrm{e}} \quad$ Refrigerating effect $(\mathrm{KJ} / \mathrm{Kg})$

$\mathrm{W}_{\mathrm{C}} \quad$ Compressor Specific work $(\mathrm{kJ} / \mathrm{kg})$

q Heat transfer rate $(\mathrm{k})$

\section{Introduction}

The thermodynamic efficiency of a refrigeration system depends mainly very much on the type of refrigerant selected. However, important practical issues such as the system design, size, initial and operating costs, safety, reliability, and serviceability on its operating temperatures esc. For a given application. Because several environmental issues like ozone layer depletion refrigeration systems refer to the different refrigerant play an important role in the performance of refrigeration cycles. The very important issue about refrigerant is the thermo physical properties [1]. Refrigerants differ in properties and to gain the preferred properties in different refrigerants. There is a trend to mix many refrigerants and using this hybrid as a new refrigerant in vapor compression cycles to enhance its performance. The different stages in the refrigeration cycle are these systems consist of an evaporator, a condenser, a compressor and an expansion valve. The evaporator is the space that needs to be cooled by the refrigerant the compressor compresses the refrigerant from the low pressure of the evaporator to the high pressure at the condenser. The heat gained by the refrigerant is rejected at the condenser and at the high pressure. Refrigerant is expanded into the low pressure evaporator by the expansion valve. The term refrigeration refers to cooling an area or substance below the environmental temperature. Replacement of an ground refrigerant by a completely modern refrigerant, for whatever cause, is an charged proposition as it may call for numerous changes. In the format and manufacturing of refrigeration systems. Subsequently it is very substantial to understand the issues connection of the selection and used to of refrigerants. In the principle, every refrigerant make be used to as a refrigerant. Air used in an air condition refrigeration system can also be assumed as a refrigerant. Hence it is very important to understand the issues related to the selection and used to of the refrigerants. 
During many researchers have reported that hybrid refrigerants alternatives refrigerant mixtures have been developed, which are summarized and mention in review of the articles [2-3]. In he replacement hydrocarbons (HCs) such as R290, R1270 and its mixtures R432A, R433A, hydroflurocarbon mixtures such as R404A, R407C and R410A and HFC/HC mixtures such as R417A and R422A are explain as the leading replacements for R22 in refrigeration, air conditioning and the heat pumps of units. The hydrocarbons such as R290 and R1270 are mentioned as the possible alternatives to R22 for residential air conditioners and heat pumps [4-7]. The hydrocarbon mixtures such as mixture contain (R290, R170), R600a (in the ratio of (98.95: 1.007: 0.0397), by mass) [8], R290/R170 mixture (in the ratio of 94:6, by mass) [9], R432A (near azeotrope mixture composed of R1270 and RE170, in the ratio of 80:20, by mass) [10], R433A (near azeotrope mixture composed of R1270 and $\mathrm{R} 290$, in the ratio of 70:30, by mass [11], mixtures of the contain (R290, R1270, RE170, R152) [12] .

\section{2- Problem description:}

In this study a group of the most common used and important refrigerants in the refrigeration process are selected. A comparative analytical study of 15 pure refrigerants with different cooling loads $(0.5$ ton ,1.0 ton ,2.0 ton ,2,5 ton and 3.0 ton ) are studied by calculating a group of their important properties such as coefficient of performance $(\mathrm{COP})$ and mass flow rate $(\dot{m})$ and work in compressor $\left(\mathrm{W}_{\mathrm{c}}\right)$ and through the results obtained by REFPROP program and graphically in a certain circumstances it becomes clear the properties of each pure refrigerant from the aforementioned refrigerants which enables us to choose the best refrigerants required for use in the mixing process, and thus obtain the new refrigerant by mixing two or more refrigerants and knowing its properties, behavior and performance, and through all the above it became possible to choose the new refrigerant in terms of performance and environmental effect if possible.

\section{3-Theoretical Analysis of refrigeration cycle}

The modest vapor compression refrigeration cycle is shown in Figure 1, at present, this system is used almost anywhere and is most
Theoretical analysis of vapour refrigeration cycle with hybrid refrigerant of different types and mixing ratios commonly used in a refrigeration arrangement. It consists of four basic attachments,

a. Compressor b. Capacitor, c. Expansion valve d. Evaporator.

The compressor in the middle of the vapor pressure system is said to compress the vapor coolant from the evaporator pressure $(\mathrm{Pe})$ to the condenser pressure $(\mathrm{Pc})$, so that the vapor can be condensed at the corresponding frame temperature (Tc), and the condenser rejects the heat from the refrigerants to the surrounding areas. So the phase change takes place from evaporative coolers to liquid, Coolants that go into the expansion valve.

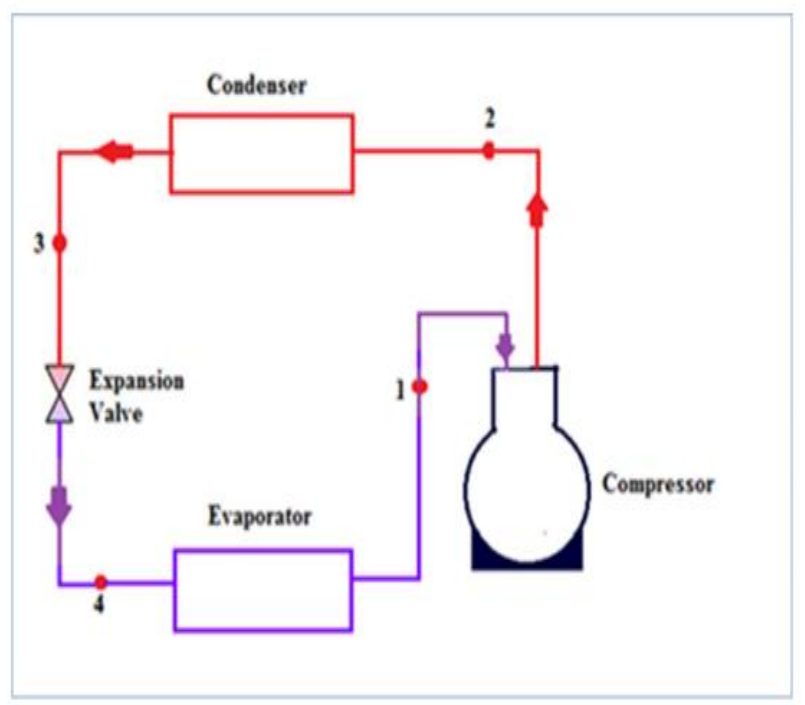

Fig.1 cycle vapor compression refrigeration

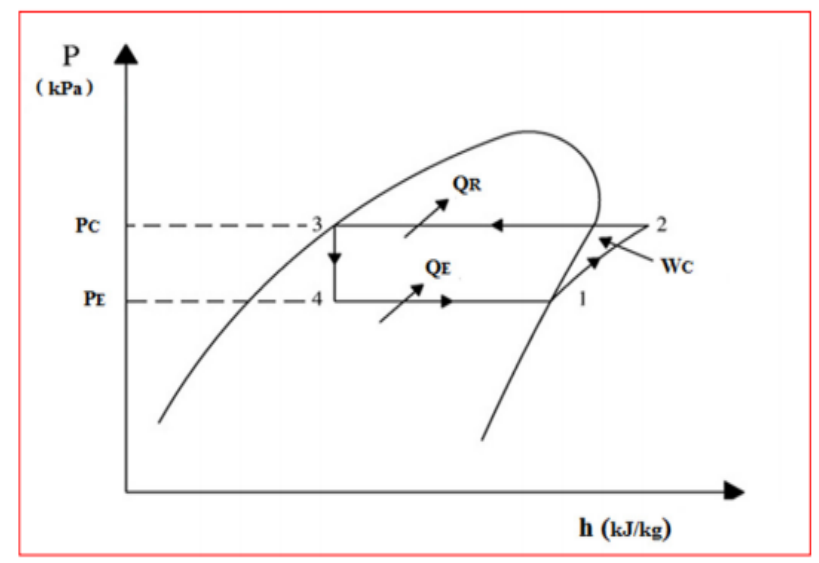

Fig.2 P-h Diagram cycle of the refrigeration

An expanding valve, also called a fluid throttle valve, expands the refrigerant from high pressure coolant to low pressure coolant. Finally, the liquid coolant enters the 
evaporator. The evaporation is obtained in the coils of low pressure and temperature, where the cooling effect is produced by absorbing the heat from the cooling compartment, and the cooling phase is transferred from the liquid coolant to the evaporative cooler, only pure vapor returns to the compressor completed the cycle [13]. And then in Figure 2, a p-h diagram () of the refrigeration cycle with four basic tasks in all cases is used in studying the refrigeration cycle by vapor pressure, the operation from 1 to 2 is the pressure, the operation of 2 to 3 is the heat expelled in the condenser, which It transfers from 3 to 4 expansions (throttling) and also works from 4 to 1 as in evaporation, that is, the heat absorbed in the evaporator. The performance characteristics of compressive work (Wc), absorbent cooling (QE) and performance parameter (COP) can be found. The performance of the refrigerator is found by the ratio of the amount of heat taken by the cold frame to the amount of work required by the compressor. This ratio is called the performance factor. The system performance is calculated as follows [6]. Working with equal pressure [14] from a coolant was discovered by.

$\mathrm{Wc}=\dot{m}(\mathrm{~h} 2-\mathrm{h} 1)$

The refrigerant effect or heat absorbed by the of liquid-vapor refrigerant during evaporation is given by

$$
\mathrm{QE}=\dot{m}(\mathrm{~h} 1-\mathrm{h} 4)
$$

The Coefficient of performance (COP) is the proportion of the heat supplant in the evaporator to work done on the compressor. $\mathrm{COP}=$ Refrigeration Effect/ Work Done (3)

$C O P_{e}=\frac{\boldsymbol{q}_{e}}{w_{C}}=\frac{h 1-h 4}{h 2-h 1}$

Ratio of the Pressure $=\frac{P_{C}}{P_{E}}$

Capacity of the order 1 TR equal (3.504) kW

Where,

$\mathrm{h} 1$ and $\mathrm{h} 2$ are Enthalpies of Refrigerant at the inlet and outlet of compressor $(\mathrm{kJ} / \mathrm{kg}) \quad \mathrm{h} 3=\mathrm{h} 4$ are Enthalpies of Refrigerant at the inlet and outlet of throttle valve $(\mathrm{kJ} / \mathrm{kg})$. For the air conditioning order of 1TR capacity, and the following processed conditions the Performance of the order can be composed as the process conditions have been chosen for
Theoretical analysis of vapour refrigeration cycle with hybrid refrigerant of different types and mixing ratios

condenser temperature of $35^{\circ} \mathrm{C}$ and evaporator temperature $-10^{\circ} \mathrm{C}$ for the theoretical of analysis, the vapor refrigerant is in arid saturated condition at the start of the compression, using P-h diagram

\section{Properties of Refrigerants}

Refrigerant selections have compromises between conflicting desirable characteristics. The working of fluid desirable characteristics are connect to thermodynamic with physical properties which carry to efficient cooling or heating operator and effective projection of supply, like high evaporation heat, big of volumetric refrigeration ability, small of temperature at the finish of the compression. And physical characteristics desirable properties of an ideal refrigerant it have talk above that there is no ideal refrigerant [15]. A refrigerant is said to be suitable when it has all of the following features :

1. High latent heat of the vaporization.

2. High critical temperature.

3. Low boiling point and low specific heat of liquid .

4. Low specific volume of vapor.

5. Non corrosive to metal.

6. Nonflammable and non-explosive.

7. Non-toxic easy to liquid at moderate pressure and temperature.

8. Easy of locating the leaks by odor or suitable indicator.

9. Mixes well the oil .

However, in this paper the attention is fundamentally focused for those fluids that can be used such as refrigerants as in the table 1 in vapor compression refrigeration system and also can be mixed together. 
Theoretical analysis of vapour refrigeration cycle with hybrid refrigerant of different types and mixing ratios and the selected refrigerants are shown below in the tables from the table ( 2 to 7 ).

Table 2. Composition of hybrid refrigerant form R125 and R134a

Table1. Properties of some pure refrigerants

\begin{tabular}{|c|c|c|c|c|}
\hline $\begin{array}{c}\text { Refriger } \\
\text { ant } \\
\text { number }\end{array}$ & $\begin{array}{c}\text { Chemical } \\
\text { Formula }\end{array}$ & $\begin{array}{c}\text { Normal } \\
\text { boiling } \\
\text { Point } \\
\left({ }^{\circ} \mathrm{C}\right.\end{array}$ & $\begin{array}{c}\text { Critical } \\
\text { temperatur } \\
\text { e }\left({ }^{\circ} \mathrm{C}\right)\end{array}$ & $\begin{array}{c}\text { Molar } \\
\text { mass } \\
\mathrm{kg} / \mathrm{kmo} \\
1\end{array}$ \\
\hline $\mathrm{R} 11$ & $\mathrm{CCI}_{3} \mathrm{~F}$ & 23.7 & 197.96 & 137.3 \\
\hline $\mathrm{R} 12$ & $\mathrm{CCI}_{2} \mathrm{~F}_{2}$ & -29.7 & 111.97 & 120.9 \\
\hline $\mathrm{R} 13$ & $\mathrm{CCIF}_{3}$ & -81.4 & 28.85 & 104.4 \\
\hline $\mathrm{R} 22$ & $\mathrm{CHCIF}_{2}$ & -40.8 & 96.145 & 86.46 \\
\hline $\mathrm{R} 23$ & $\mathrm{CHF}_{3}$ & -82.1 & 26.143 & 70.01 \\
\hline $\mathrm{R} 41$ & $\mathrm{CH}_{3} \mathrm{~F}$ & -78.3 & 44.13 & 34.03 \\
\hline $\mathrm{R} 115$ & $\mathrm{C}_{2} \mathrm{CIF}_{5}$ & -39.2 & 79.95 & 154.4 \\
\hline $\mathrm{R} 116$ & $\mathrm{C}_{2} \mathrm{~F}_{6}$ & -78.1 & 19.88 & 138.0 \\
\hline $\mathrm{R} 124$ & $\mathrm{C}_{2} \mathrm{HCIF}_{4}$ & -11.9 & 122.28 & 136.4 \\
\hline $\mathrm{R} 125$ & $\mathrm{C}_{2} \mathrm{H}_{2} \mathrm{~F}_{4}$ & -48.1 & 66.023 & 120.0 \\
\hline $\mathrm{R} 134 \mathrm{a}$ & $\mathrm{C}_{2} \mathrm{H}_{2} \mathrm{~F}_{4}$ & -26.1 & 101.06 & 102.0 \\
\hline $\mathrm{R} 142 \mathrm{~b}$ & $\mathrm{C}_{2} \mathrm{H}_{3} \mathrm{CIF}_{2}$ & -9.1 & 137.11 & 100.5 \\
\hline $\mathrm{R} 143 \mathrm{a}$ & $\mathrm{C}_{2} \mathrm{H}_{3} \mathrm{~F}_{3}$ & -47.2 & 72.707 & 84.04 \\
\hline $\mathrm{R} 152 \mathrm{a}$ & $\mathrm{C}_{2} \mathrm{H}_{4} \mathrm{~F}_{2}$ & -24.1 & 113.2 & 66.05 \\
\hline
\end{tabular}

\section{5- Calculations:}

REFPROP is short to the Reference fluid Properties. This software, was it created by the National Institute of Standards and Technology (NIST). symbolizes (NIST). The thermodynamic and transport properties of industrially substantial liquids and their combination can be calculated by this software, depending on the mass mixing ratio, pressure and temperature. The results can be presented in plots and tables during the graphical user moderator they them too open during data is arranged or user written implementation incoming their REFPROP [16]. An analytical calculations were carried out by the REFPROP.program, first by choosing the units system that Its adopt to analyze the required and specific data, and then the substance window opens, from which the define new mixing window opens, which selects the refrigerants to be mixed and also determines the ratios for each refrigerant. Then we do the calculations by opening the calculate window and then choosing saturation table through which we specify the assumed temperature from specify saturation table after that we opening input property range window , where the program then calculates the required characteristics of the new hybrid refrigerants as the enthalpy and entropy values are then chosen to be used later to calculate cop and other properties by the Excel program, as well as the value of $h$ is obtained at the superheated through from $\mathrm{p}$-h diagram in the plot window where is selected after that the value of $\mathrm{h} 2$ is obtained, which It is also used to extract the previously mentioned values. The above mentioned mixing ratios

\begin{tabular}{|c|c|c|}
\hline New Ref.MIX & $\begin{array}{c}\text { R125 } \\
\text { Mass fraction }\end{array}$ & $\begin{array}{c}\text { R134s } \\
\text { Mass fraction }\end{array}$ \\
\hline RMD11 & 0.50 & 0.50 \\
\hline RMD12 & 0.25 & 0.75 \\
\hline RMD13 & 0.75 & 0.25 \\
\hline
\end{tabular}

Table3. Composition of hybrid refrigerant form R115,R124 and R134a

\begin{tabular}{|c|c|c|c|}
\hline $\begin{array}{c}\text { New } \\
\text { Ref.MIX }\end{array}$ & $\begin{array}{c}\text { R115 } \\
\text { Mass } \\
\text { fraction }\end{array}$ & $\begin{array}{c}\text { R124 } \\
\text { Mass } \\
\text { fraction }\end{array}$ & $\begin{array}{c}\text { R134a } \\
\text { Mass } \\
\text { fraction }\end{array}$ \\
\hline RMD31 & 0.333 & 0.333 & 0.333 \\
\hline RMD32 & 0.50 & 0.20 & 0.30 \\
\hline RMD33 & 0.30 & 0.50 & 0.20 \\
\hline RMD34 & 0.20 & 0.30 & 0.50 \\
\hline
\end{tabular}

Table 4. Composition of hybrid refrigerant form R22 and R134a

\begin{tabular}{|c|c|c|}
\hline New Ref.MIX & $\begin{array}{c}\text { R22 } \\
\text { Mass fraction }\end{array}$ & $\begin{array}{c}\text { R134a } \\
\text { Mass fraction }\end{array}$ \\
\hline RMD41 & 0.25 & 0.75 \\
\hline RMD42 & 0.50 & 0.50 \\
\hline RMD43 & 0.75 & 0.25 \\
\hline
\end{tabular}

Table 5. Composition of hybrid refrigerant form $\mathrm{R} 134 \mathrm{a}, \mathrm{R} 22$ and R115

\begin{tabular}{|c|c|c|c|}
\hline $\begin{array}{c}\text { New } \\
\text { Ref.MIX }\end{array}$ & $\begin{array}{c}\text { R134a } \\
\text { Mass } \\
\text { fraction }\end{array}$ & $\begin{array}{c}\text { R22 } \\
\text { Mass } \\
\text { fraction }\end{array}$ & $\begin{array}{c}\text { R125 } \\
\text { Mass } \\
\text { fraction }\end{array}$ \\
\hline RMD51 & 0.33 .3 & 0.33 .3 & 0.33 .3 \\
\hline RMD52 & 0.50 & 0.20 & 0.30 \\
\hline RMD53 & 0.30 & 0.50 & 0.20 \\
\hline RMD54 & 0.20 & 0.30 & 0.50 \\
\hline
\end{tabular}

Table 6. Composition of hybrid refrigerant form R115 and R125

\begin{tabular}{|c|c|c|}
\hline New Ref.MIX & $\begin{array}{c}\text { R115 } \\
\text { Mass fraction }\end{array}$ & $\begin{array}{c}\text { R125 } \\
\text { Mass fraction }\end{array}$ \\
\hline RMD61 & 0.25 & 0.75 \\
\hline RMD62 & 0.50 & 0.50 \\
\hline RMD63 & 0.75 & 0.25 \\
\hline
\end{tabular}

\section{6- Results and discussion:}

Fig.3 shows the variation of work in compressor with the amount of heat for two refrigerants (R125, R 134a) in the pure state and the mixing process with mixing ratios (50: $50),(75: 25),(25: 75)$ respectively as shown in table (2) noticed that the work value needed to absorb the same amount of the heat for R125 is greater than for R134a. In the case of mixing 
the work value is lowered compared with that for R125 and it is directly proportional to the mixing ratio due to low latent heat of vaporization of R125 compared with R134a and also high critical temperature of R134a .

Fig.4 expresses the variation of work in compressor with the amount of heat for three refrigerants and their mixtures with different mixing ratios as shown in the table 3 this figure show that the work value important to absorb the amount of the heat by the evaporator for the R115 refrigerant is very high compared with the work required to absorb as the amount of heat by the evaporator for the R134 refrigerant. For the amount of work required for the refrigerant R124 it is gave an medium value between R134 and R 115. In the case of mixing the mixtueres results showed a very clear improvement in the performance of the hybrid refrigerant, which differed greatly from the performance of the R115 refrigerant alone, and the performance of the rest of the refrigerants due to the high value of the latent heat of vaporization of the refrigerant R134a and the critical temperature compared with the rest of the refrigerants as shown in Table 1 and also because of high specific volume of vapor of R115.

Fig.5 represents the relationship between the required work in the compressor and the amount of heat absorbed in the evaporator for a pair of refrigerants and their mixtures with different mixing ratios as shown in Table (4) where it can note that the mixtures absorb the highest amount of heat compared with the refrigerants in the pure state due to good thermal properties of mixtures because for the high latent heat of vaporization of $\mathrm{R} \mathrm{134a}$ and also the low boiling point of R22 as shown in table 1, and low the specific volume of evaporation for R22.

Fig.6 represents the relationship between the required work in the compressor with the amount of heat absorbed in the evaporator for three pure refrigerants R134, R22 and $\mathrm{R} 125$ and their mixtures as shown in table (5). We note that the refrigerant 125 gives the lowest amount of heat absorbed compared with the rest of the refrigerants, due to low
Theoretical analysis of vapour refrigeration cycle with hybrid refrigerant of different types and mixing ratios

critical temperature and high specific volume and have bad thermal proprties compaered to other refrgerants, and also we notice that R134 gives high amount of heat absorbed due to high latent heat of vaporization for this refrigerant and low poiling point temparture , while for R22 refrigerant, it has the low boiling point. When mixing these refrigerants, the mixtures results gives an intermediate result between the results of the pure refrigerants due to the refrgeranta some thermal properties and their characteristics.

Fig.7 represents the relationship between the required work in the compressor and the amount of heat absorbed in the evaporator for a pair of pure refrigerants R115 and R125 and their hybrid refrigerants in table 6, where noticed the highest work expended for R115 due to the low critical temperature and high the specific volume and when the percentage of R125 in the mixture increases, the value of the work required to absorb the amount of heat increases due to the low value of critical temperature and high specific volume and also low the latent heat of vaporization .

Fig. 8 represents variation the coefficient of performance (cop) and compressor ratio for pair refrigerants (R125,R134a) and their mixtures for different ratio as shown in table 2.It can be seen that the maximum value coefficient of performance record at pure refrigerant R134a due to high latent heat and low poling point temperature and other good thermal proprieties to the refrigerant and also it can be seen that minimal value coefficient of performance at R125 where the values resulting from mixing were intermediate values between the values of the above refrigerants before mixing due to some thermal properties as boiling temperature point and critical temperature, latent heat of the vaporization, specific heat of the liquid and specific volume of vapor .

Figs.(9-11) represent variation the coefficient of performance (cop) and compressor ratio for the selected pure refrigerants and their mixtures with different ratio as shown in tables (3-5). It can be shown so as to the maximum the performance recorded with $\mathrm{R} 134 \mathrm{a}$ and the minimum value 
with R115 while the values of performance for the mixtures fluctuated between the maximum and minimum values for the pure refrigerants and the cause this back to the latent heat of the refrigerant where the refrigerant $\mathrm{R} 134 \mathrm{a}$ has the maximum latent heat.

Fig.12 represents variation the coefficient of performance (cop) and compressor ratio for pair refrigerants (R115,R125) and their mixtures with different ratio as shown in table 6 where noted the highest values the coefficient of performance at R125 compared with R115 due to low boiling point temparture and specific valume of R125, when mixed the results be are not good becuase some their thermal properties as leten heat of vaporization and also noticed high compressor ratio of their the mixtures because high specific volume of vapor its .

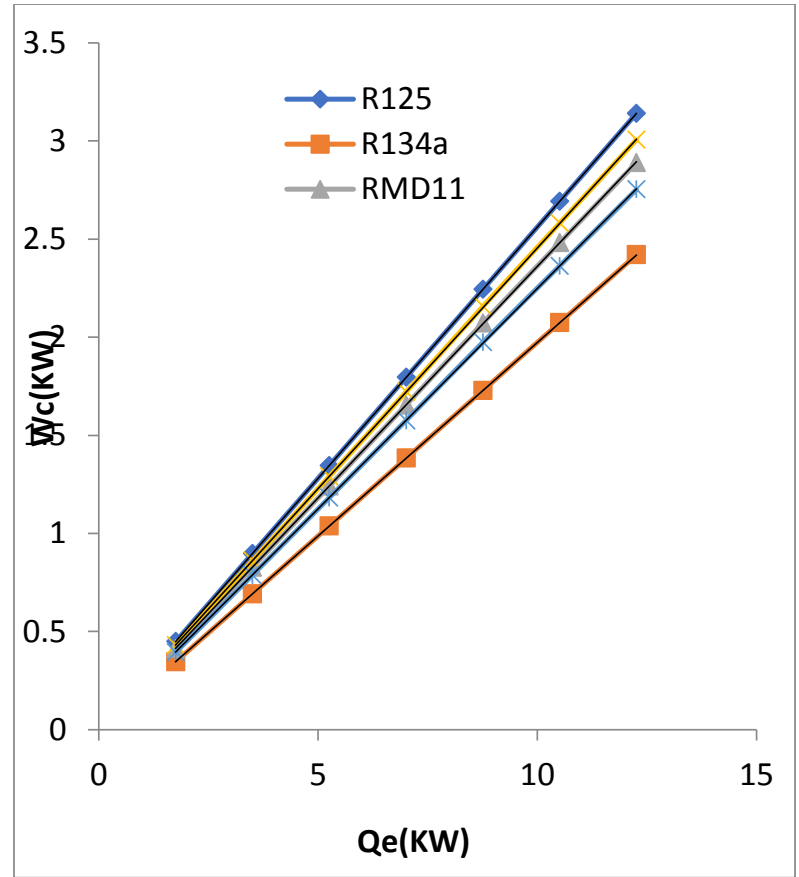

Fig.3 Variation of the work with refrigerating effect for R125, R134a and mixture.
Theoretical analysis of vapour refrigeration cycle with hybrid refrigerant of different types and mixing ratios

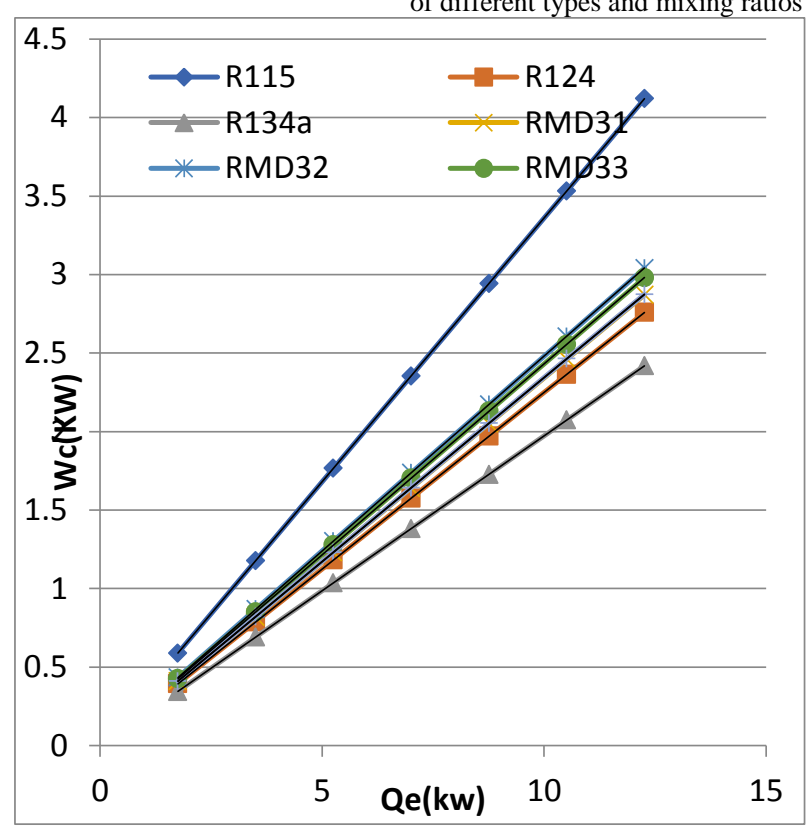

Fig.4 Variation of the work with Refrigerating effect for R115, R124, R134a and their mixtures.

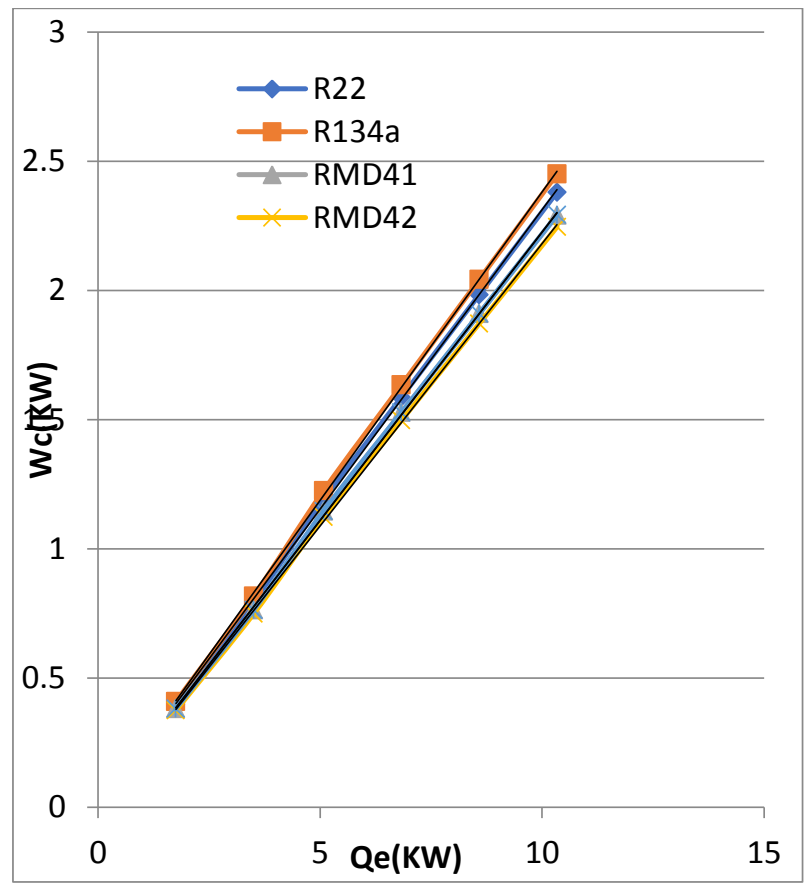

Fig.5 Variation of the work with refrigerating effect for R22, R134a and their mixtures. 


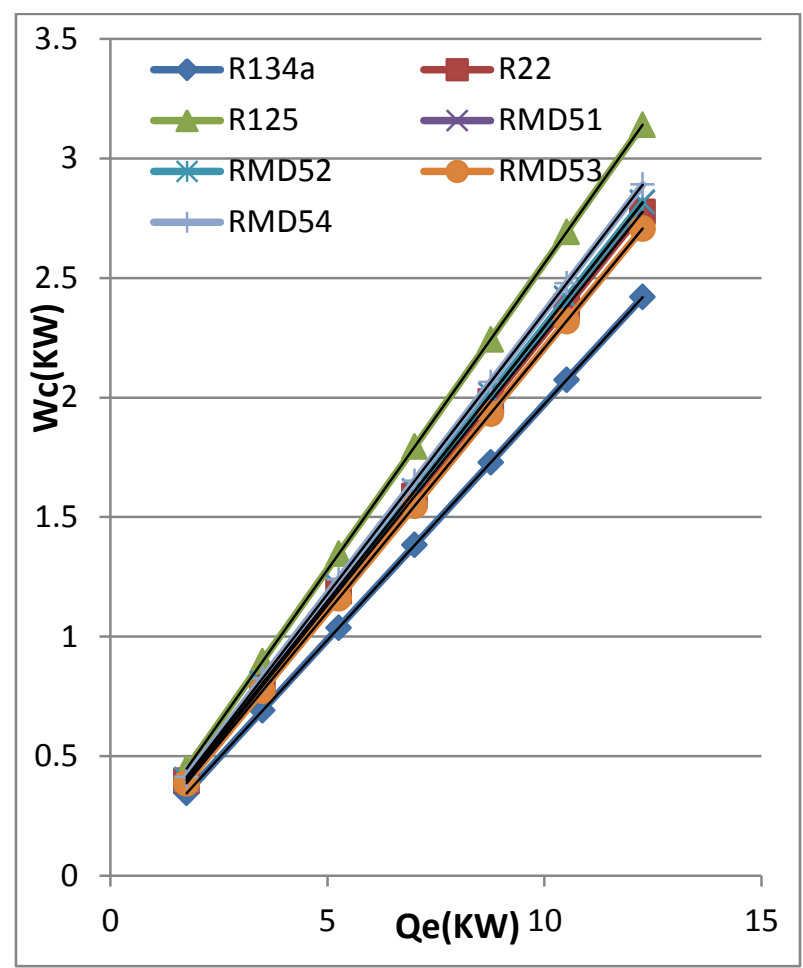

Fig.6 Variation of the work with Refrigerating effect for R134a, R22, R125 and their mixtures.

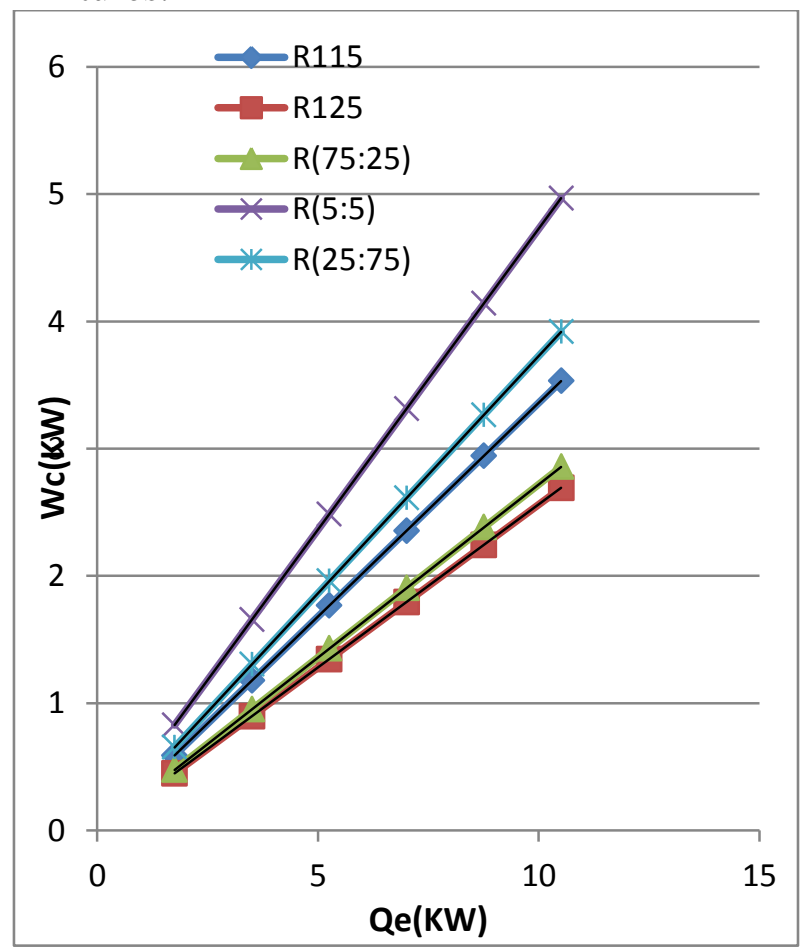

Fig.7 Variation of the work with Refrigerating effect for R115,R125 and their mixtures .
Theoretical analysis of vapour refrigeration cycle with hybrid refrigerant
of different types and mixing ratios

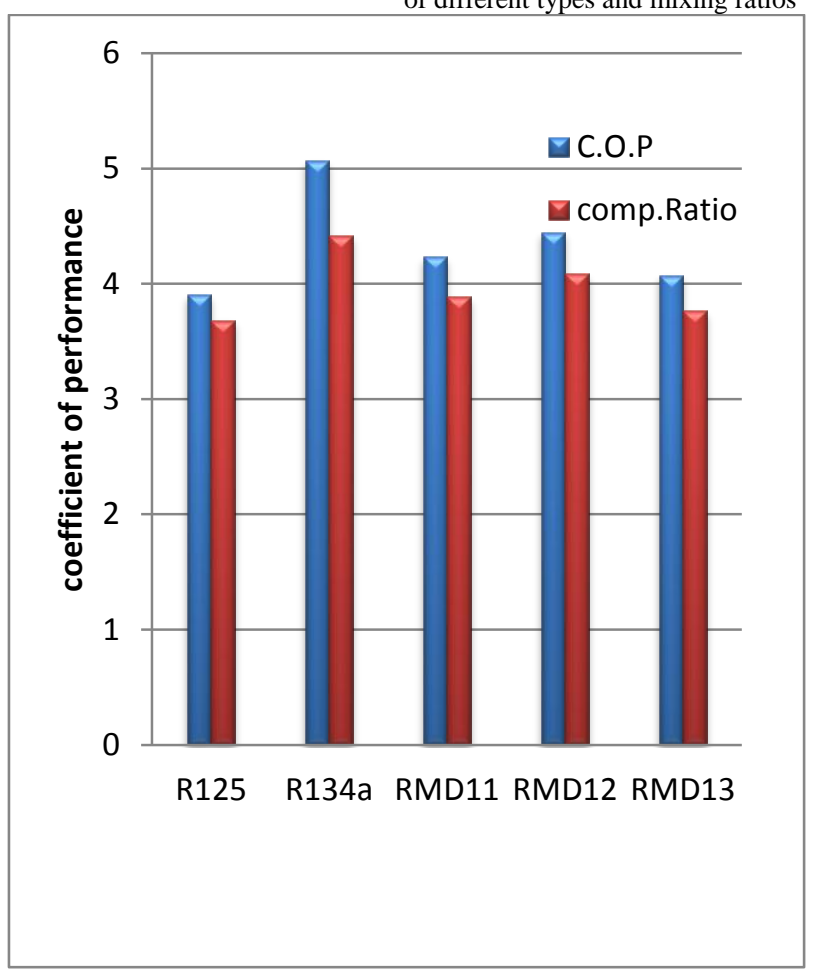

Fig.8 Variation the coefficient of performance and compressor ratio for pair (R125,R134a) and their mixtures.

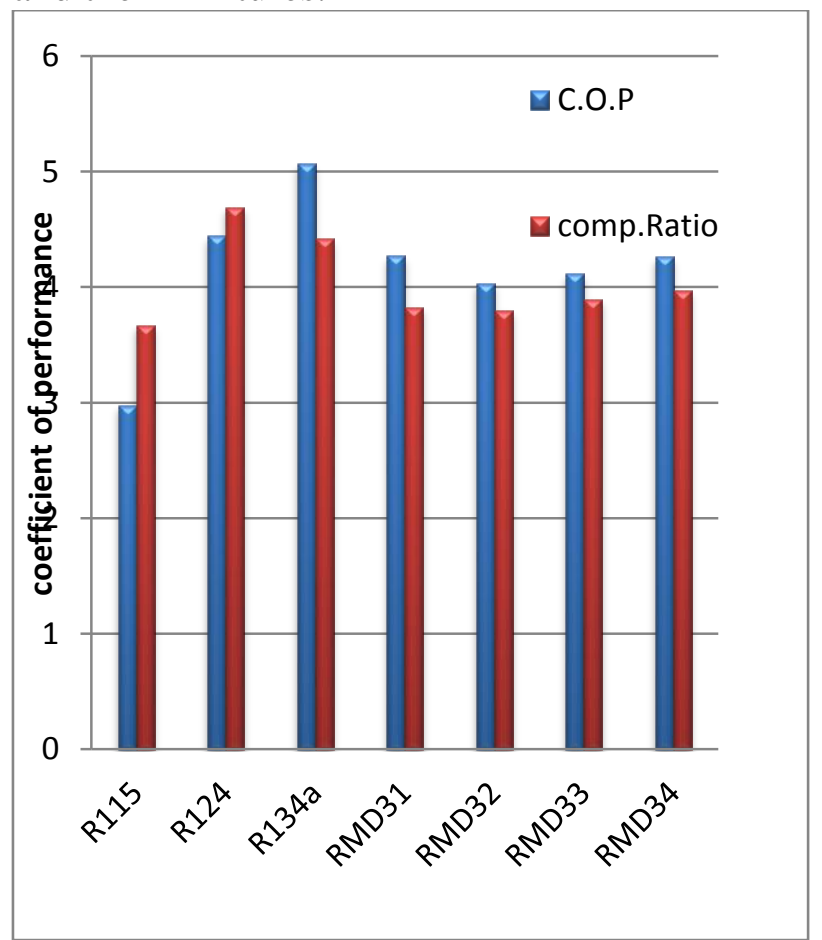

Fig.9 Variation the coefficient of performance and compressor ratio for pair (R115,R124,R134a) and their mixtures. 


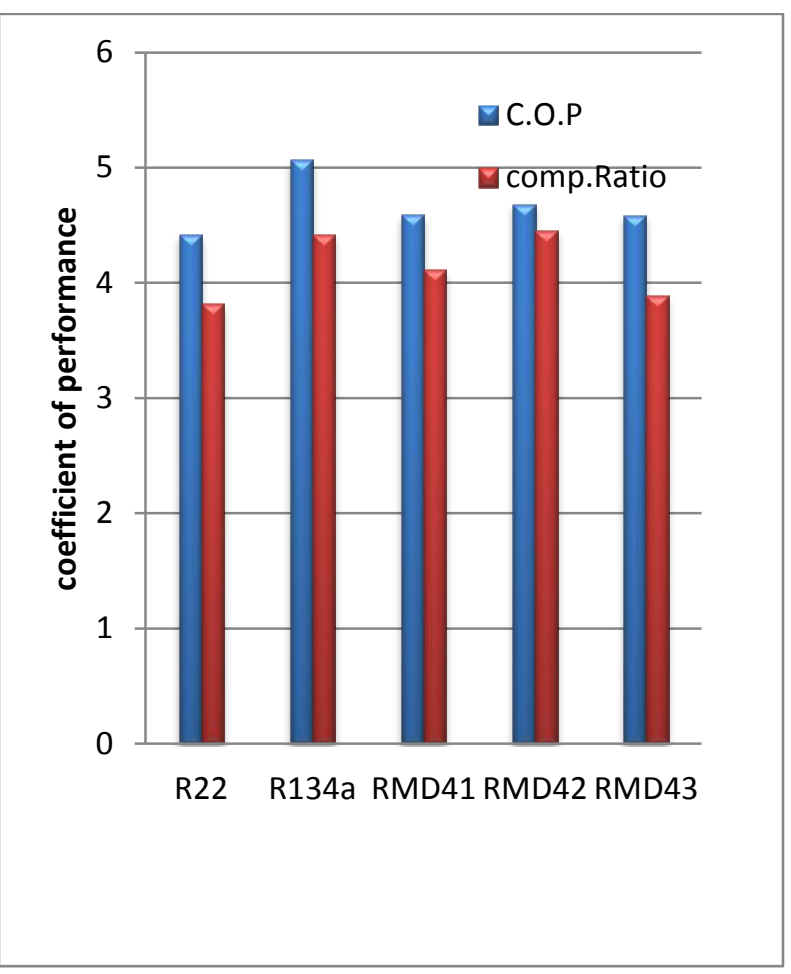

Fig.10 the Variation of coefficie of performance and compressor ratio for pair (R22,R134a) and their mixtures.

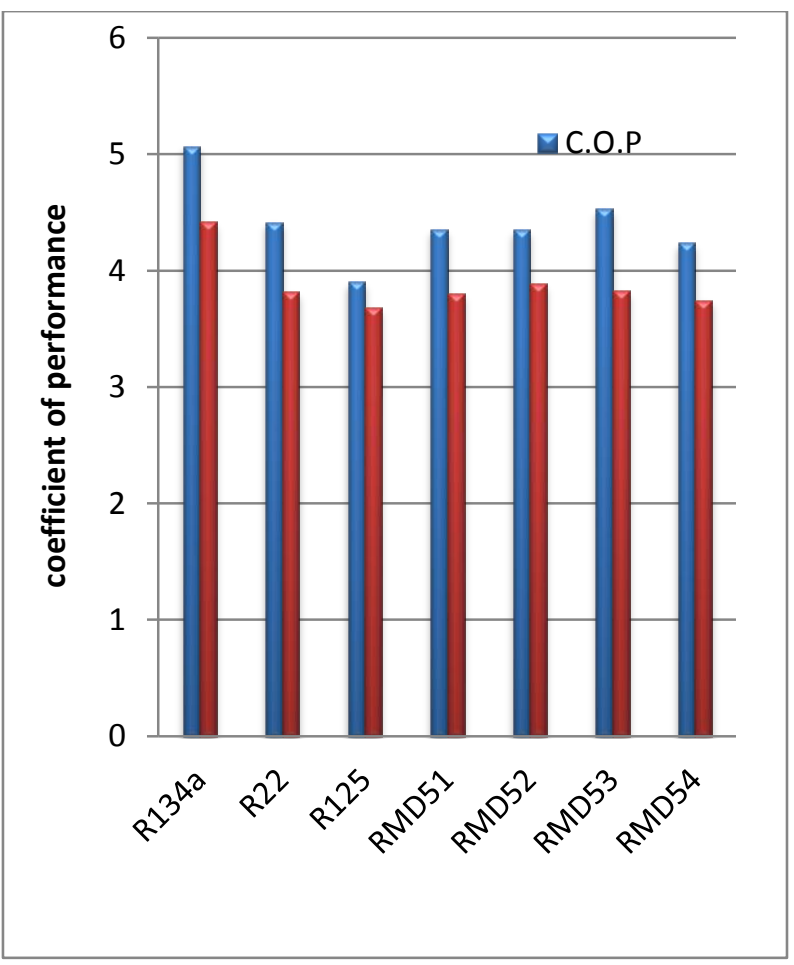

Fig.11 The variation of the coefficient performance and compressor ratio for pair (R134a,R22,R125) and their mixtures.
Theoretical analysis of vapour refrigeration cycle with hybrid refrigerant of different types and mixing ratios

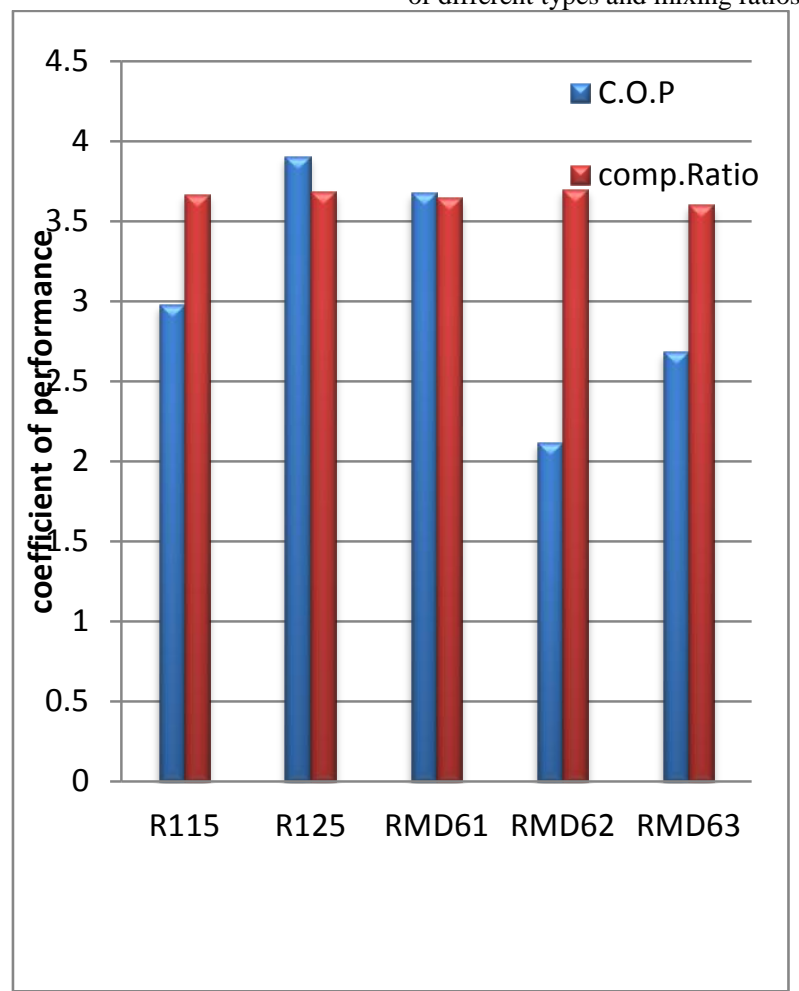

Fig.12 the Variation of coefficient of performance and compressor ratio to pair (R115,R125) and their mixtures .

\section{Conclusions:}

After carrying out the analytical study on a group of pure refrigerants with the desired properties and characteristics according to the criteria previously discussed.

1-Concluded when mixing of $25 \% \mathrm{R} 125$ and $75 \%$ R134a gives a new hybrid refrigerant a good thermal properties as it absorbs $12.26 \mathrm{kwatt}$ at the lowest work used equal to 0.394 kwatt, compared of the rest ratios, and also give out the highest coefficient of performance of equal 4.44 . As well as when mixing $50 \% \mathrm{R} 22$ and $50 \% \mathrm{R} 134 \mathrm{a}$, it is forming a new refrigerant with different characteristics and high efficiency and coefficient of performance equal 4.68. and give highest refrigerating effect in evaporator $10.34 \mathrm{kwatt}$ at the work in compressor $2,25 \mathrm{kwatt}$.

2-Also, from the apparent results we notice that, some refrigerants when mixed with other refrigerants do not give the required properties. Where we found out when mixing R115 with R125 in the proportions of $50 \%$ for each refrigerant or $25 \% \mathrm{R} 115$ with $75 \% \mathrm{R} 125$ the results are not good such as give the lowest for coefficient of performance equal 2.1 as 
well as highest of the work used near 5.1 kwatt.

\section{References:}

[1] E. Navarro, I.O. Mart1'nez-Galvan, J. Nohales, J. Gonza'lvez-Macia. ,Comparative experimental study of an open piston compressor working with R-1234yf, R-134a and R-290, .international journal of refrigeration, v36 (2 0113$)$ pages $768-775$.

[2] M. Mohanraj, S. Jayaraj, and C. Muraleedharan, "Environment friendly alternatives to halogenated refrigerants," A rev. J Green House Gas Control, 2009, 3, 108119.

[3] Z. Yang, and $\mathrm{X}$. Wu, "Retrofits and options for the alternatives to HCFC22," Energy, 2013, 59, 1-21.

[4] Y. S. Chang, M. S. Kim, and S. T. Ro, "Performance and heat transfer characteristics of hydrocarbon refrigerants in a heat pump system,” J Refrig., 2000, 23, 232-242.

[5] E. Granryd, "Hydrocarbons as refrigerants- an overview," J Refrig. 2001, $24,15-24$.

[6] J. F. Urchueguía, J. M. Corberán, J. Gonzálvez, and J. M. Díaz, "Experimental characterization of a commercial-size scroll and reciprocating compressor working with R22 and propane (R290) as refrigerant, Ecobibrium," J AIRAH. 23-25.

[7] S. Devotta, A.S. Padalkarb, and N. K. Sane, "Performance assessment of HC290 as a drop-in substitute to HCFC-22 in a window air conditioner," J Refrig., 2005, 28, 594-604.

[8] B. Purkayastha, and P. K. Bansal, "Experimental study on HC290 and a commercial liquefied petroleum gas (LPG) mix as suitable replacements for HCFC22," J Refrig., 1998, 21, 3- 17.

[9] K. J. Park, and D.S. Jung, "Performance of heat pumps charged with R170/R290 mixture," Appl. Energy, 2009, 86, 25982603.
Theoretical analysis of vapour refrigeration cycle with hybrid refrigerant of different types and mixing ratios

[10] K. J. Park, Y. B. Shim, and D. Jung, "Experimental performance of R432A to replace R22 in residential air conditioners and heat pumps," Appl. Therm. Eng., 2009, 29597-600.

[11] K. J. Park, Y. B. Shim, and D.S. Jung, "Performance of R433A for replacing HCFC22 used in residential air conditioners and heat pumps," Appl. Energy 2008, 85, 896900.

[12] K. J. Park, and D.S. Jung, "Thermodynamic performance of HCFC22 alternative refrigerants for residential air conditioning applications," Energy build., 2007, 39, 675680 .

[13] Yan, G., Hu, H., \& Yu, J. (2015). Performance evaluation on an internal autocascade refrigeration cycle with mixture refrigerant R290/R600a. Applied Thermal Engineering, 75, pp.994-1000.

[14] Wang, H., Peterson, R., Harada, K., Miller, E., Ingram-Goble, R., Fisher, L. \& Ward, C. (2011). Performance of a combined organic Rankine cycle and vapor compression cycle for heat activated cooling. Energy, 36(1), pp.447-458.

[15] Park, K. J., Lee, Y., \& Jung, D. (2010). Performance of R170/R1270 mixture under air-conditioning and heat pumping conditions. Journal of mechanical science and technology, 24(4), pp.879-885. [16] Lemmon, E. W., Huber, M. L., \& McLinden, M. O. (2013). NIST reference database 23: reference fluid thermodynamic and transport propertiesREFPROP, version 9.1. Standard Reference Data Program. 